\title{
The Influence of Menopause on Inflammatory Cytokine and Adipocytokines Profile in Saudi Women
}

\author{
Mohammed H Saiem Al-Dahr* \\ Department of Medical Laboratory Technology, King Abdulaziz University, Saudi Arabia
}

Submission: April 04, 2019; Published: May 10, 2019

"Corresponding author: Mohammed H Saiem Al-Dahr, Department of Medical Laboratory Technology, Faculty of Applied Medical Sciences, King Abdulaziz University, P.0. Box 80324, Jeddah, 21589, Saudi Arabia

Abstract

Background: Menopause is characterized with reduction in serum estrogen level which leads to some physiological changes in addition to high risk of some diseases as cardiovascular disorders.

Objective: This study was designed to measure menopausal-related changes in circulating level of adipocytokines and systemic inflammation cytokines profile among Saudi women. Material and

Methods: Two hundred Saudi women were selected from the out-patient of the Gynecology and Obstetrics Department, King Abdalaziz Teaching Hospital, there were non-smokers and with no hormonal replacement therapy were enrolled for the study. Relative to their hormonal status, the participants were divided in two study groups: group (A) premenopausal women included one hundred women and the mean of their age was $36.53 \pm 4.27$ year, while group (B) included one hundred women and the mean of their age was $54.28 \pm 5.63$ year.

Results: The mean value of tumor necrosis factor - alpha (TNF- $\alpha$ ), Interleukin-6 (IL-6), Interleukin-10 (IL-10), C-reactive protein (CRP) and leptin in were significantly higher in group(A) than group(B). However, there was a statistically significant decrease in serum levels of resistin and adiponectin in group (B) than group (A).

Conclusion: The was an alteration in serum adipocytokines and inflammatory cytokines profile among postmenopausal Saudi women.

Keywords: Menopause; Inflammatory cytokines; Adipocytokines; Postmenopausal women; Adiponectin; Serum levels; Interleukin-6; Menstrual bleeding; Genetic factors; Mitogen; Metabolic regulator; Mitogenic; Proangiogenic factor; Obesity, Insulin resistance

Abbreviations: DHEA: Dehydroepiandrosterone; CRP: C-Reactive Protein; TNF- $\alpha$ Tumor Necrosis Factor-Alpha; IFN- $\alpha$ : Interferon-Alpha; IL-4: Interleukin-4; BMI: Body Mass Index

\section{Introduction}

Menopause is a commonly used term to refer to the period of climacteric that encompasses the transitional period between the reproductive years up to and beyond the last episode of menstrual bleeding and genetic factors play important role in determining the average age of menopause, whoever, recently women has greater than the third of life after menopause [1].

Menopause is associated with many physiological changes and risk of many disorders in body systems due to reduced serum level of estrogen [2]. Cytokines play an important role in regulation of many immune system responses, however serum level of some cytokines found to be changed after menopause like increased level of interleukin (IL-6) and interleukin-8 (IL-8) and reduction of tumor necrosis factor-alpha (TNF- $\alpha$ ) as well as higher level of macrophage colony-stimulating factor [3]. However, another study reported decrease in serum level of interferon-alpha (IFN$\alpha$ ) and interleukin-4 (IL-4) [4]. Alteration in cytokines found to be associated with high risk of cardiovascular disorders [5-7].

Adipokines, as leptin, adiponectin, visfatin, and resistin, are produced by different fat depots, including subcutaneous, visceral, and mammary adipose tissues $[8,9]$. The most prominent adipokine, leptin, was first described as a neurohormone whose primary function is to regulate energy balance and food intake in the hypothalamus. Subsequent studies found that leptin can modulate several processes in the peripheral organs, such as immune response, fertility, and hematopoiesis. On a cellular level, leptin has been found to act as a mitogen, metabolic regulator, motogenic, and proangiogenic factor [10]. New evidence suggests 
that leptin could be involved in tumorigenesis, especially in the development of breast, colorectal, and prostate cancers [11]. Adiponectin is another adipocyte-derived peptide hormone that is inversely associated with adiposity [12]. Adiponectin is a strong indicator of insulin sensitivity wherein its decline precedes the onset of obesity and insulin resistance [13] and may be one mechanism through which obesity alters breast cancer risk. Mantzoros et al. [14] found an inverse association between serum adiponectin levels and breast cancer risk among postmenopausal women.

The aim of this study was to examine the examined the influence of menopausal status on adipocytokines, and inflammatory cytokines profile in Saudi women.

\section{Patients and Methods}

\section{Subjects}

One hundred Saudi premenopausal women (mean age $36.53 \pm 4.27$ years, mean body mass index (BMI $=22.83 \pm 2.66 \mathrm{~kg}$ / $\mathrm{m} 2$ ) and 100 postmenopausal (mean age $54.28 \pm 5.63$ years, mean BMI $=23.71 \pm 2.25 \mathrm{~kg} / \mathrm{m} 2$ ) at the King Abdulaziz Teaching Hospital, Medical Faculty's Gynecology and Obstetrics Department were admitted to the study. Based on menstrual history, we considered women to be postmenopausal, if they had at least 12 consecutive months of amenorrhea with no other medical cause. While women were considered premenopausal, if they had regular periods in the years preceding their examination. We restricted analyses to non-pregnant premenopausal women who did not take oral contraceptives.

Exclusion criteria were history of breast or genital tract malignancy, or hepatic, renal, vascular, or endocrine disease and acute infection; as well as those reporting tobacco and alcohol use. All volunteers were asked to read and sign an informed consent document prior to participation, in addition this study was approved by the Scientific Ethical Committee, Faculty of Applied Medical Sciences, King Abdulalziz University.

\section{Laboratory analysis}

For the biochemical estimations, venous blood samples were collected between 7:00 A.M. and 9:00 A.M. after fasting overnight and the samples were allowed to clot. Thereafter, the samples were centrifuged and divided into aliquots and stored at $-70^{\circ} \mathrm{C}$ until assayed.

a) Serum adiponectin, leptin, resistin, visfatin measurement: The levels of adiponectin in human serum were determined using adiponectin ELISA (Phoenix Pharmaceuticals, Inc., Belmont, CA). Serum leptin, resistin, and visfatin levels were detected using ELISA (Phoenix Pharmaceuticals).

b) Measurement of inflammatory cytokines: Interleukin-6 (IL-6) and interleukin-10 (IL-10) levels were analyzed by "Immulite 2000" immunassay analyzer (Siemens Healthcare Diagnostics, Deerfield, USA). However, tumor necrosis factor-alpha (TNF- $\alpha$ ) and C-reactive protein (CRP) levels were measured by ELISA kits (ELX 50) in addition to ELISA microplate reader (ELX 808; BioTek Instruments, USA).

\section{Statistical analysis}

The mean values of the investigated parameters obtained before and after three months in both groups were compared using paired " $\mathrm{t}$ " test. Independent " $\mathrm{t}$ " test was used for the comparison between the two groups $(\mathrm{P}<0.05)$.

\section{Results}

Table 1 shows the baseline characteristics of the participants who entered the trial. There was no significant differences in baseline characteristics related to age, height, body weight, body mass index and waist hip ratio between the two groups were found, in addition to significant differences in systolic blood pressure, diastolic blood pressure, triglyceride, total cholesterol, low density lipoprotein cholesterol, high density lipoprotein cholesterol and glucose between both groups.

Table 1: Baseline characteristics of the study participants according to menopausal status.

\begin{tabular}{|c|c|c|c|}
\hline Characteristic & Premenopausal Women & Postmenopausal Women & Significance \\
\hline Age (years) & $36.53 \pm 4.27$ & $54.28 \pm 5.63^{*}$ & $\mathrm{P}<0.05$ \\
\hline Height (cm) & $158.38 \pm 6.21$ & $156.13 \pm 5.84$ & $\mathrm{P}>0.05$ \\
\hline Body weight (kg) & $55.81 \pm 4.62$ & $58.34 \pm 4.37$ & $\mathrm{P}>0.05$ \\
\hline Body mass index (kg/m²) & $22.83 \pm 2.66$ & $23.71 \pm 2.25$ & $\mathrm{P}>0.05$ \\
\hline Waist hip ratio & $0.86 \pm 0.02$ & $0.87 \pm 0.03$ & $\mathrm{P}>0.05$ \\
\hline SBP (mmHg) & $103.29 \pm 8.92$ & $117.23 \pm 9.26^{*}$ & $\mathrm{P}<0.05$ \\
\hline DBP (mmHg) & $75.62 \pm 6.14$ & $76.8 \pm 5.93^{*}$ & $\mathrm{P}<0.05$ \\
\hline Triglyceride (mg/dL) & $93.29 \pm 5.61$ & $96.58 \pm 4.86^{*}$ & $\mathrm{P}<0.05$ \\
\hline Total cholesterol (mg/dL) & $179.31 \pm 10.22$ & $210.39 \pm 13.31^{*}$ & $\mathrm{P}<0.05$ \\
\hline LDL- cholesterol (mg/dL) & $105.94 \pm 7.85$ & $130.42 \pm 12.18^{*}$ & $\mathrm{P}<0.05$ \\
\hline HDL- cholesterol (mg/dL) & $57.37 \pm 4.56$ & $59.28 \pm 4.57^{*}$ & $\mathrm{P}<0.05$ \\
\hline Glucose (mg/dL) & $85.63 \pm 5.19$ & $92.72 \pm 6.32^{*}$ & $\mathrm{P}<0.05$ \\
\hline
\end{tabular}

SBP: Systolic Blood Pressure; DBP: Diastolic Blood Pressure; LDL: Low Density Lipoprotein; HDL: High Density Lipoprotein; (*) indicates a significant difference between the two groups, $\mathrm{P}<0.05$. 
The serum levels of TNF- $\alpha$, IL-6, IL-10, CRP and leptin in women with natural postmenopausal women were significantly higher than in premenopausal women. However, there was a statistically significant decrease in serum levels of resistin and adiponectin in postmenopausal women than premenopausal women (Table 2).

Table 2: Comparison of serum levels of TNF- $\alpha$, IL-4, IL-6, IL-10, IL-12, CRP, leptin, adiponectin and resistin in study groups.

\begin{tabular}{|c|c|c|c|c|}
\hline \multirow{2}{*}{} & \multicolumn{2}{|c|}{ Mean + SD } & t- Value & Significance \\
\cline { 2 - 5 } & Premenopausal & Postmenopausal & & $\mathrm{P}<0.05$ \\
\hline TNF- $\alpha(\mathrm{pg} / \mathrm{mL})$ & $5.87 \pm 1.26$ & $8.13 \pm 1.85^{*}$ & 6.23 & $\mathrm{P}<0.05$ \\
\hline IL-6 $(\mathrm{pg} / \mathrm{mL})$ & $2.61 \pm 0.63$ & $5.35 \pm 1.18^{*}$ & 6.72 & $\mathrm{P}<0.05$ \\
\hline IL-10 $(\mathrm{pg} / \mathrm{mL})$ & $12.44 \pm 3.57$ & $16.32 \pm 4.13^{*}$ & 5.65 & $\mathrm{P}<0.05$ \\
\hline CRP $(\mathrm{mg} / \mathrm{L})$ & $2.43 \pm 0.92$ & $4.18 \pm 1.34^{*}$ & 5.26 & $\mathrm{P}<0.05$ \\
\hline Leptin $(\mathrm{ng} / \mathrm{ml})$ & $11.27 \pm 3.93$ & $23.63 \pm 7.52^{*}$ & 6.14 & $\mathrm{P}<0.05$ \\
\hline Adiponectin $(\mu \mathrm{g} / \mathrm{ml})$ & $14.18 \pm 3.25$ & $6.22 \pm 3.58^{*}$ & 5.22 & $\mathrm{P}<0.05$ \\
\hline Resistin $(\mathrm{ng} / \mathrm{mL})$ & $43.67 \pm 9.14$ & $21.4 \pm 5.33^{*}$ & 7.54 & \\
\hline
\end{tabular}

TNF-a: Tumor Necrosis Factor - alpha; IL-6: Interleukin-6; IL-10: Interleukin-10; CRP: C-Reactive Protein; ( ${ }^{*}$ Indicates a significant difference between the two groups, $\mathrm{P}<0.05$.

\section{Discussion}

Menopause is a turning point in every woman's life, the final episode of menstrual bleeding associated with cessation of the activity of ovarian follicle, resulting in the permanent cessation of menstruation. The onset of menopause is generally associated with a hormone deficiency, which is a contributory factor for the increased incidence of osteoporosis, cardiovascular diseases, vasomotor disturbances and cognitive deterioration. we examined the influence of menopausal status on adipocytokines, and inflammatory cytokines profile secretion. Concerning the inflammatory cytokines profile, the results of the present study demonstrate that women in post-menopause present, as compared with their premenopausal counterparts, an alteration in serum cytokine profile characterized by higher concentrations of circulating IL-6, TNF- $\alpha$, IL-10 and CRP were determined to be elevated in healthy, non-obese postmenopausal women. These data observed in our study is consistent with the findings from previous studies on healthy populations $[15,16]$.

Many studies also reported an increase in pro-inflammatory serum markers, particularly IL-6 after menopause and suggested that in addition to age, in postmenopausal women, changes of the immune system have been attributed to estrogen deprivation [3,17-19]. It has also been reported that IL-6 concentrations are usually elevated in postmenopausal women even in absence of infection or trauma since the regulation of IL- 6 synthesis is impaired with age [20-22]. The increase in concentrations of proinflammatory cytokines such as IL- 6 after menopause may be associated with the functions of monocytes and macrophages due to estrogen deficiency. In addition, the change in serum IL-6 concentration has been reported to be correlated with alterations in serum dehydroepiandrosterone (DHEA) and DHEA-sulfate levels, the changes in these hormones as well as estrogen may affect the secretion of cytokines from monocytes and macrophages [17]. Malutan \& colleagues [23] stated that serum level of IL-1 $\beta$, IL-8 and TNF- $\alpha$ in women with natural menopause and in women with surgically induced menopause is significantly higher than in premenopausal women in the control group.

Vural et al. [24] stated that postmenopausal women have increased plasma TNF- $\alpha$, IL-4, IL-10 and IL-12 concentrations in comparison with premenopausal individuals. The increase of anti-inflammatory IL-10, IL-12 and especially IL-4 is probably a compensatory mechanism, by which these cytokines counteract to pro-inflammatory TNF- $\alpha$, and thus balance its osteoclast activating and oxidative stress inducing effects. Vassalle et al. [25] stated that menopausal status is associated with increased systolic and diastolic pressure $(\mathrm{p}<0.05)$, higher IL-6 $(\mathrm{p}<0.05)$ and TNF alpha $(p<0.01)$, and lower antioxidants $(p<0.01)$. In the other hand, Sites and colleagues proved that the level of TNF-alpha was higher in postmenopausal compared to premenopausal women (4.81 +/1.99 vs. $3.54+/-0.85$ pg/mL). Interleukin-6 and CRP did not differ by menopausal status [26]. The difference in these results may be due to the difference in methods of measurement.

Our results revealed that serum levels of adipocytokines (included adiponectin, leptin and resistin) were different according to the menopausal status, serum levels of adiponectin and leptin were significantly increased, while serum level of resistin was significantly decreased among postmenopausal women. Our findings were consistent with Tamakoshi et al. [27] proved that adiponectin levels in postmenopausal women were also significantly higher than those in premenopausal women $[10.3(9.95,10.7)$ vs $9.04(8.71,9.39), P=0.028]$. Similarly, Sowers and colleagues proved that the resistin levels were approximately two times higher during premenopause compared to peri- or postmenopause and there were significantly lower adiponectin and higher ghrelin levels in the perimenopause stage, compared to either the pre- or postmenopause stage [28]. In the other hand, Ben et al. [29] stated that Premenopausal women had significantly higher leptin and L/A ratio and lower adiponectin levels than postmenopausal women. In addition, Krentz \& colleagues [30] found that serum leptin was higher (mean 25.70 \pm 15.67 
vs $14.94+9.89 \mathrm{ng} / \mathrm{mL}, \mathrm{P}<0.01$ ) and adiponectin lower (mean $11.72 \pm 4.80$ vs $17.31 \pm 7.45 \mu \mathrm{g} / \mathrm{mL}, \mathrm{P}<0.01$ ) in postmenopausal women with polycystic ovary syndrome versus premenopausal women with polycystic ovary syndrome. Sherk et al. [31] concluded that increases in fat mass, not menopause per se, contributes to higher leptin levels in older women and age differences in leptin concentrations were no longer significant after controlling for fat mass. Lecke \& colleagues [32] suggested that obese individuals exhibit both leptin resistance and decreased serum adiponectin levels, where progressive increase in adiposity throughout life rather than menopausal status seems to influence the relationship between leptin and adiponectin in women. Douchi \& coworkers [33] found that serum leptin levels in premenopausal women $8.4+/-4.8 \mathrm{ng} / \mathrm{ml}$, which did not differ from that in postmenopausal women $(9.2+/-7.1 \mathrm{ng} / \mathrm{ml})$ that means that menopausal status does not have a significant impact on leptin production. The contradictory results could be due to different selection of patients.

\section{Conclusion}

The current study provides evidence that post menopause present an alteration in serum adipocytokines and inflammatory cytokines profile. Such changes should be taken into account when tailoring menopausal therapies to their specific requirements.

\section{Acknowledgment}

This project was funded by the Deanship of Scientific Research (DSR) at King Abdulaziz University, Jeddah, under grant no. (G-2142-39). The authors, therefore, acknowledge with thanks DSR for technical and financial support.

\section{References}

1. Utian WH (1980) Menopause in modern perspective. AppletonCentury-Crofts, New York, USA.

2. Cioffi M, Esposito K, Vietri MT, Gazzerro P, D’Auria A, et al. (2002) Cytokine pattern in postmenopause. Maturitas 41(3): 187-192.

3. Kamada M, Irahara M, Maegawa M, Ohmoto Y, Takeji T, et al. (2001) Postmenopausal changes in serum cytokine levels and hormone replacement therapy. Am J Obstet Gynecol 184(3): 309-314.

4. Kumru S, Godekmerdan A, Yilmaz B (2004) Immune effects of surgical menopause and estrogen replacement therapy in peri-menopausal women. J Reprod Immunol 63(1): 31-38.

5. Pradhan AD, LaCroix AZ, Langer RD, Trevisan $\mathrm{M}$, Lewis $\mathrm{CE}$, et al (2004) Tissue plasminogen activator antigen and D-dimer as markers for atherothrombotic risk among healthy postmenopausal women. Circulation 110(3): 292-300.

6. Pradhan AD, Manson JE, Rifai N, Buring JE, Ridker PM (2001) C-reactive protein, interleukin 6 , and risk of developing type 2 diabetes mellitus. JAMA 286(3): 327-334.

7. Pradhan AD, Manson JE, Rossouw JE, Siscovick DS, Mouton CP, et al. (2002) Inflammatory biomarkers, hormone replacement therapy, and incident coronary heart disease: prospective analysis from the Women's Health Initiative observational study. JAMA 288(8): 980-987.

8. Vona-Davis L, Rose DP (2007) Adipokines as endocrine, paracrine, and autocrine factors in breast cancer risk and progression. EndocrineRelated Cancer 14(2): 189-206.
9. Schäffler A, Schölmerich J, Buechler C (2007) Mechanisms of disease: adipokines and breast cancer-endocrine and paracrine mechanisms that connect adiposity and breast cancer. Nat Clin Pract Endocrinol Metab 3(4): 345-354.

10. Hu X, Juneja SC, Maihle NJ, Cleary MP (2002) Leptin-a growth factor in normal and malignant breast cells and for normal mammary gland development. J Natl Cancer Inst 94(22): 1704-1711.

11. Garofalo C, Surmacz E (2006) Leptin and cancer. J Cell Physiol 207(1): $12-22$.

12. Kelesidis I, Kelesidis T, Mantzoros CS (2006) Adiponectin and cancer: a systematic review. Br J Cancer 94(9): 1221-1225.

13. Kershaw EE, Flier JS (2004) Adipose tissue as an endocrine organ. J Clin Endocrinol Metab 89(6): 2548-2556.

14. Mantzoros C, Petridou E, Dessypris N, Chavelas C, Dalamaga M, et al (2004) Adiponectin and breast cancer risk. J Clin Endocrinol Metab 89(3): 1102-1107.

15. Ferrucci L, Corsi A, Lauretani F, Bandinelli S, Bartali B, et al. (2005) The origins of age-related proinflammatory state. Blood 105(6): 22942299.

16. Kim OY, Chae JS, Paik JK, Seo HS, Jang Y, et al. (2012) Effects of aging and menopause on serum interleukin-6 levels and peripheral blood mononuclear cell cytokine production in healthy nonobese women. Age (Dordr) 34(2): 415-425.

17. Cioffi M, Esposito K, Vietri MT (2002) Cytocine pattern in postmenopause. Maturitas 41: 187-192.

18. Gameiro CM, Romão F, Castelo-Branco C (2010) Menopause and aging: changes in the immune system-a review. Maturitas 67(4): 316-320.

19. Yasui T, Maegawa M, Tomita J, Miyatani Y, Yamada M, et al. (2007) Changes in serum cytokine concentrations during the menopausal transition. Maturitas 56(4): 396-403.

20. Ershler WB (1993) Interleukin-6: a cytokine for gerontologists. J Am Geriatr Soc 41(2): 176-181.

21. Daynes RA, Araneo BA, Ershler WB, Maloney C, Li GZ, et al. (1993) Altered regulation of IL-6 production with normal aging. J Immunol 150(12): 5219-5230.

22. Lutgendorf SK, Garand L, Buckwalter KC, Reimer TT, Hong SY, et al. (1999) Life stress, mood disturbance, and elevated interleukin-6 in healthy older women. J Gerontol 54(9): 434-439.

23. Malutan AM, Dan M, Nicolae C, Carmen M (2014) Proinflammatory and anti-inflammatory cytokine changes related to menopause. Prz Menopauzalny 13(3): 162-168.

24. Vural P, Canbaz M, Akgul C (2006) Effects of menopause and postmenopausal tibolone treatment on plasma TNF alpha, IL-4, IL-10, IL-12 cytokine pattern and some bone turnover markers. Pharmacol Res 53(4): 367-371.

25. Vassalle C, Cicinelli E, Lello S, Mercuri A, Battaglia D, et al. (2011) Effects of menopause and tibolone on different cardiovascular biomarkers in healthy women. Gynecol Endocrinol 27(3): 163-169.

26. Sites CK, Toth MJ, Cushman M, L' Hommedieu GD, Tchernof A, et al. (2002) Menopause-related differences in inflammation markers and their relationship to body fat distribution and insulin-stimulated glucose disposal. Fertil Steril 77(1): 128-135.

27. Tamakoshi K, Yatsuya H, Wada K, Matsushita K, Otsuka R, et al. (2007) The transition to menopause reinforces adiponectin production and its contribution to improvement of insulin-resistant state. Clin Endocrinol (Oxf) 66(1): 65-71. 
28. Sowers MR, Wildman RP, Mancuso P, Eyvazzadeh AD, KarvonenGutierrez CA, et al. (2008) Change in adipocytokines and ghrelin with menopause. Maturitas 59(2): 149-157.

29. Ben Ali S, Jemaa R, Ftouhi B, Kallel A, Feki M, et al. (2011) Relationship of plasma leptin and adiponectin concentrations with menopausal status in Tunisian women. Cytokine 56(2): 338-342

30. Krentz AJ, von Mühlen D, Barrett-Connor E (2012) Adipocytokine profiles in a putative novel postmenopausal polycystic ovary syndrome (PCOS) phenotype parallel those in premenopausal PCOS: the Rancho Bernardo Study. Metabolism 61(9): 1238-1241.
31. Sherk VD, Malone SP, Bemben MG, Knehans AW, Palmer IJ, et al. (2011) Leptin, fat mass, and bone mineral density in healthy pre- and postmenopausal women. J Clin Densitom 14(3): 321-325.

32. Lecke SB, Morsch DM, Spritzer PM (2011) Leptin and adiponectin in the female life course. Braz J Med Biol Res 44(5): 381-387.

33. Douchi T, Iwamoto I, Yoshimitsu N, Kosha S, Nagata Y (2002) Leptin production in pre- and postmenopausal women. Maturitas 42(3): 219223

\section{Your next submission with JuniperPublishers will reach you the below assets}

- Quality Editorial service

- Swift Peer Review

- Reprints availability

- E-prints Service

- Manuscript Podcast for convenient understanding

- Global attainment for your research

- Manuscript accessibility in different formats

( Pdf, E-pub, Full Text, audio)

- Unceasing customer service

Track the below URL for one-step submission https://juniperpublishers.com/online-submission.php 